\title{
Effect of HPMC and ethyl cellulose polymeric granules and its combinations in press coated tablets of lornoxicam: fabrication and in vitro characterization
}

\author{
*S. Dineshmohan ${ }^{1}$, V R M Gupta ${ }^{2}$, A. Ramesh ${ }^{1}$, V. Harika ${ }^{1}$ and T. Sravani ${ }^{1}$ \\ ${ }^{1}$ Dept. of Pharmaceutics, Vishnu Institute of Pharmaceutical Education and Research Narsapur-502313, Medak, Telangana, India \\ ${ }^{2}$ Dept. of Pharmaceutics, Pullareddy Institute of Pharmacy, Annaram-502313 Medak, Hyderabad, Telangana, India
}

\begin{abstract}
The main objective of the present exploration was to formulate and evaluate chronomodulated press-coated tablets to deliver the NSAID lornoxicam, when a pain in the joints, functional disability persist in the early morning time is typically observed in most Rheumatoid arthritis (RA) patients. Pre formulation studies and drug excipient compatibility studies were carried out for lornoxicam and excipients. Core tablets containing lornoxicam was prepared by direct compression method and the tablets were subjected to various pre-compression and post-compression parameters (C1-C4 formula) based on the above result best core tablet batch was selected and used for press coating processes. HPMC and EC granules were used as controlled release polymers in the outer layer. These tablets were subjected to pre and post compression parameters, finally the tablets were evaluated for lag time and in vitro dissolution. Results of preformulation studies were acceptable limits. No interaction was observed between lornoxicam and excipients by FTIR. The results of pre and post compression studies were within limits. Formulation code CC3 was identified as best formulation that extends a release profile with $6 \mathrm{~h}$ lag time followed by complete lornoxicam release after 8 h. From the graphical representation it can be well perceive that this is perfectly fit in to Korsemeyer which had a Regression coefficient $\left(\mathrm{R}^{2}\right)$ of 0.9431 . The results of the in-vitro release data of this layer were fitted to the Korsemeyer-Peppas equation to examine the release pattern of the drug from the polymeric system. The drug release was identified as super case II transport as the " $\mathrm{n}$ " value found to be more than 0.89 .
\end{abstract}

Key Words: lornoxicam, chronomodulated, Rheumatoid arthritis, Core tablets and press coating processes.

\section{INTRODUCTION}

Rheumatoid arthritis is a chronic disease and it destroys the joints integrity. In patients of rheumatoid arthritis, symptoms such as pain in the joints and functional disability mainly persist in the early morning time after awakening (Agarwal et al., 2011). Plasma C-reactive protein (CRP) levels, is an indicator of inflammatory responses in RA. It has been recommended to treat rheumatoid arthritis by using the concept of chronopharmacotherapy to ensure that the highest blood levels of the drug should be available to treat the peak pain and stiffness. A pulsatile drug delivery system which can be administered at night, i.e., before sleep, but releases the drug during the early morning time would be a promising chronopharmaceutic system (Najmuddin et al., 2010; Buttgereit, 2011). These types of delivery systems deliver the drug at the time when the symptoms of the disease are at its peak within a period of 24 hours. They rapidly release the drug after a lag time, i.e., a period of no drug release (Singh et al., 2012). Drug targeting to the colon has been found as a useful approach for delaying the drug absorption, and it usually requires for the treatment of diseases that are having symptoms in the early morning time like rheumatoid arthritis (Rajput et al., 2012; Abhinetri et al., 2013). Compression coated tablets are one such delivery systems through which drugs can be easily targeted to the colon (Mothilal et al., 2012). Lornoxicam belongs to the class of NSAIDs and is more effective for treating the pain and inflammation of rheumatoid
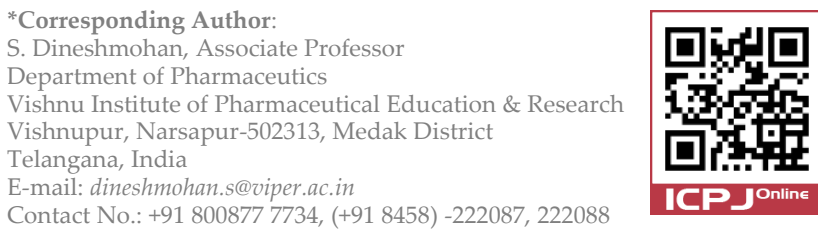

arthritis (Kidd and Frenzel, 1996; Zhang et al., 2005). To Keep in view of targeting lornoxicam during the time of its greatest need in rheumatoid arthritis, we have fabricated compression coated lornoxicam tablets as a pulsatile drug delivery system.

\section{MATERIALS AND METHODS}

\section{Materials}

Lornoxicam was obtained as a complimentary sample by Smilax labs, Hyderabad, India. Hydroxypropylmethyl cellulose (HPMC) and Ethyl cellulose (EC) were received from Yeluri formulations, Hyderabad, India. Eudragit was procured from Degussa Evonik industries, Mumbai, India. All other chemicals used were of analytical grade.

\section{Methods}

Construction of calibration curve of lornoxicam

Standard stock solution was prepared by dissolving 100 $\mathrm{mg}$ of lornoxicam in $100 \mathrm{ml}$ of mobile phase to get concentration of $1 \mathrm{mg} / \mathrm{ml}$. Mobile phase was containing $0.05 \mathrm{M} \mathrm{NaOH}$ solution for this $0.2 \mathrm{gm}$ of $\mathrm{NaOH}$ dissolved in $100 \mathrm{ml}$ of distilled water. The prepared stock solution was further diluted with mobile phase to get working standard solution of 5, 10, 15, 20 and $25 \mathrm{mcg}$ of lornoxicam to construct Beer's law plot for the pure drug, the absorbance was measured at $\lambda \max$ at $380 \mathrm{~nm}$, against mobile phase as blank. The standard graph was plotted by taking concentration of drug on $\mathrm{X}$-axis and absorbance on $\mathrm{Y}$-axis in the concentration range of 5-25 mcg (Bendale et al., 2011).

\section{Drug and excipients compatibility studies}

An FTIR study was performed to determine the compatibility of drug and excipients. FTIR spectra of pure drug and compressed tablets were recorded with a FTIR spectrophotometer (Shimadzu Corporation, Japan, 8400s) 
using $\mathrm{KBr}$ disc method. The disc was placed in the sample holder and scanned from 4000 to $500 \mathrm{~cm}^{-1}$ at a resolution of $1 \mathrm{~cm}^{-1}$ (Rane et al., 2009)

\section{Preparation of Lornoxicam core tablets}

The core tablets of lornoxicam were prepared by direct compression method. For the preparation of core tablets, microcrystalline cellulose was used as diluents and croscarmellose sodium was used as a superdisintegrant, Magnesium Stearate was used as a lubricant and purified talc was used as a glidant. Totally 100 tablets were prepared, all the ingredients were mixed together in a mortar and pestle for 20mins (Narendra and Srinath, 2010). A theoretical weight of about $100 \mathrm{mg}$ powder was fed manually in to die of 10 stations, tablet compression machines (Mini Press, 1-10 Karnavati, Gujarat, India) using $6 \mathrm{~mm}$ flat faced punch and die to obtain the core tablet. Different formulation batches of lornoxicam core tablets are shown in (table 1 ).

\section{Compression coating of Lornoxicam core tablets}

The core tablets were press coated with polymer granules of HPMC and Ethyl cellulose. Two types of granules were prepared by using two different polymers, i.e., HPMC and Ethyl cellulose. The granules were formed by simple mixing of polymer with $5 \% \mathrm{w} / \mathrm{v}$ alcoholic solution of polyvinyl pyrollidone K30 to form dough. The formed dough was passed through sieve, dried and resieved through sieve no. 20 and finally, mixed with talc and magnesium stearate (Bajpai et al., 2012). The core tablets were press coated with polymer granules of HPMC and Ethyl cellulose (table 2). One half of the polymeric powders were filled in the die cavity to make a powder bed at the bottom of a tablet compression machine using a suitable punch. The core tablet $(100 \mathrm{mg})$ was placed in the center on the above powder bed, followed by filling of the remaining half quantity of the polymer powder. The tablet was then compressed and the press coated tablets were evaluated and used for further coating.

Enteric coating of compression coated lornoxicam tablets $2.5 \mathrm{gm}$ Eudragit and $0.25 \mathrm{ml}$ of PEG were dissolved in 100 $\mathrm{ml}$ of isopropyl alcohol and acetone at 1:1 ratio by using a magnetic stirrer. Then the tables were dipped on to the solution and dried at room temperature for 24 hours and kept in a vacuum desiccator (Sharma et al., 2013). Quantity of the ingredients is shown in (table 3 ).

\section{Characterization of core tablets}

The prepared powder blend for core tablets was evaluated for various pre-compression parameters like angle of repose, bulk and tapped density, Carr's compressibility index and Hausner's ratio and post-compression parameters such as hardness, thickness, weight variation, friability, in vitro disintegration time, drug content uniformity and in vitro dissolution (Rao et al., 2011).

Table 1: Calibration curve data of Lornoxicam.

\begin{tabular}{ccc}
\hline S. No & Concentration $(\boldsymbol{\mu g} / \mathbf{m l})$ & Absorbance \\
\hline 0 & 0 & 0 \\
1 & 5 & 0.169 \\
2 & 10 & 0.359 \\
3 & 15 & 0.567 \\
4 & 20 & 0.721 \\
5 & 25 & 0.896 \\
\hline
\end{tabular}

Characterization of compression-coated tablets

Prepared tablets were subjected to quality control tests, including hardness, friability, weight variation, water uptake test, In vitro dissolution test and uniformity of drug content (Bashardoust et al., 2013; Jagdale et al., 2010; Dandale et al., 2013).

\section{Release kinetics of compression-coated lornoxicam tablets}

To scrutinize the mode of release from tablets, release data were analyzed using the following mathematical models:

Zero-order kinetics $\mathrm{Q}_{\mathrm{t}}=\mathrm{Q}_{0}-\mathrm{K}_{\mathrm{t}} \mathrm{t}$

First-order kinetics $\ln \mathrm{Q}_{\mathrm{t}}=\ln \mathrm{Q}_{0}-\mathrm{K}_{1 \mathrm{t}}$

Higuchi equation $Q_{t}=K_{2} t^{1 / 2}$

Peppas equation $\mathrm{Q} / \mathrm{Q}_{0}=\mathrm{K} \mathrm{t}^{\mathrm{n}}$

where $K_{0}, K_{1}$ and $K_{2}$, are release rate constants, $Q / Q_{0}$ is the fraction of drug released at time $t, Q_{0}$ is the initial amount of drug, $Q_{t}$ is the amount of drug released at time $t, K$ is a constant, and $\mathrm{n}$ is a diffusion constant that indicates general operating release mechanism. The exponent $\mathrm{n}$ is calculated through the slope of the straight line (table 2), which indicates the mechanism of drug release (Thakkar et al., 2009; Chithaluru et al., 2011; Khamanga \& Walker, 2011).

\section{Stability studies}

The purpose of stability testing is to provide evidence on how the quality of drug product varies with time under the influence of a variety of environmental factors such as temperature, humidity, and light. The optimized press coated tablets were subjected to stability studies (as per $\mathrm{ICH}$ guidelines) at $40 \pm 2^{\circ} \mathrm{C} / 75 \pm 5 \% \mathrm{RH}$ in a humidity chamber. The products were evaluated for their physical characteristics and in-vitro drug release profiles over a period of 3 months.

\section{RESULTS AND DISCUSSION}

The calibration curve of lornoxicam in $0.05 \mathrm{M} \mathrm{NaOH}$ at 379 $\mathrm{nm}$ was plotted between concentrations versus absorbance. It follows the Beer-Lambert's law in the range of 5-25 $\mu \mathrm{g} / \mathrm{ml}$ and coefficient of correlation was found to be 0.998 .

Fourier-transform infrared (FTIR) spectra were scanned over the wave number range of $4000-500 \mathrm{~cm}^{-1}$. They showed characteristic peaks of lornoxicam at 3059.20 $\mathrm{cm}^{-1}$ corresponding to-NH stretching vibration. The intense absorption peak was found at $1637.52 \mathrm{~cm}^{-1}$ due to stretching vibration of the $\mathrm{C}=\mathrm{O}$ group in primary amide. Other peaks were observed at 1585.18 and $1539.25 \mathrm{~cm}^{-1}$ and were assigned to bending vibrations of the $\mathrm{N}-\mathrm{H}$ group in the secondary amide. The stretching vibrations of the $\mathrm{O}=\mathrm{S}=\mathrm{O}$ group appeared at 1155.40, 1377.22 and $1329.07 \mathrm{~cm}^{-1}$. Other prominent peaks appeared at 829.42 $\mathrm{cm}^{-1}$ corresponding to $-\mathrm{CH}$ aromatic ring bending and hetero aromatics and at $781.20 \mathrm{~cm}^{-1}$ due to $\mathrm{C}-\mathrm{Cl}$ bending vibrations. The optimized formulation CC3 showed characteristic peak at $3063.06 \mathrm{~cm}^{-1}$ corresponding to $-\mathrm{NH}$ stretching vibration. The intense absorption peak was
Table 2: Composition of Lornoxicam core tablet.

\begin{tabular}{clcccc}
\hline S. & \multirow{2}{*}{ Ingredients in $(\mathbf{m g})$} & \multicolumn{4}{c}{ Formulation code } \\
\cline { 3 - 6 } No & $\mathrm{C}_{1}$ & $\mathrm{C}_{2}$ & $\mathrm{C}_{3}$ & $\mathrm{C}_{4}$ \\
\hline 1 & Lornoxicam & 8 & 8 & 8 & 8 \\
2 & Micro Crystalline Cellulose & 87.5 & 85 & 82.5 & 80 \\
3 & Cross carmellose sodium & 2.5 & 5 & 7.5 & 10 \\
4 & Magnesium Stearate & 1 & 1 & 1 & 1 \\
5 & Talc & 1 & 1 & 1 & 1 \\
6 & Total weight of the tablet & 100 & 100 & 100 & 100 \\
\hline
\end{tabular}


Table 3: Pre-compression parameters for core tablets.

\begin{tabular}{ccccc}
\hline S. & Parameters & $\mathbf{C}_{1}$ & $\mathbf{C}_{2}$ & $\mathbf{C}_{3}$ \\
No & Bulk Density $(\mathrm{gm} / \mathrm{ml})$ & $0.45 \pm 0.01$ & $0.43 \pm 0.01$ & $0.47 \pm 0.02$ \\
\hline 1 & Tapped Density $(\mathrm{gm} / \mathrm{ml})$ & $0.50 \pm 0.015$ & $0.54 \pm 0.011$ & $0.54 \pm 0.02$ \\
2 & Carr's Index $(\%)$ & $12.48 \pm 0.27$ & $12.88 \pm 0.26$ & $12.89 \pm 0.14$ \\
3 & Hausner's Ratio $(\%)$ & $1.15 \pm 0.011$ & $1.17 \pm 0.010$ & $1.13 \pm 0.022$ \\
4 & Angle of Repose $(\theta)$ & $27.78 \pm 0.02$ & $28.08 \pm 0.02$ & $12.68 \pm 0.11$ \\
5 & & & $26.06 \pm 0.01$ \\
\hline
\end{tabular}

Table 4: Post-compression parameters for core tablets.

\begin{tabular}{|c|c|c|c|c|c|}
\hline \multirow{2}{*}{$\begin{array}{l}\text { S. } \\
\text { No }\end{array}$} & \multirow{2}{*}{ Parameters } & \multicolumn{4}{|c|}{ Core Tablet } \\
\hline & & $\mathrm{C}_{1}$ & $\mathrm{C}_{2}$ & $\mathrm{C}_{3}$ & $\mathrm{C}_{4}$ \\
\hline 1 & Thickness mm & $2.6 \pm 0.11$ & $2.4 \pm 0.17$ & $2.4 \pm 0.17$ & $2.5 \pm 0.05$ \\
\hline 2 & Hardness $\mathrm{Kg} / \mathrm{cm}^{2}$ & $3.5 \pm 0.15$ & $3.8 \pm 0.17$ & $3.5 \pm 0.20$ & $3.6 \pm 0.15$ \\
\hline 3 & Friability\% & 0.7 & 0.7 & 0.8 & 0.8 \\
\hline 4 & DT (Sec) & $30 \pm 0.06$ & $32 \pm 0.05$ & $31 \pm 0.02$ & $18 \pm 0.02$ \\
\hline 5 & Drug Content \% & $100.25 \pm 0.01$ & $97.28 \pm 0.03$ & $98.28 \pm 0.02$ & $98.77 \pm 0.01$ \\
\hline 6 & Wt Deviation\% & $99 \pm 0.01$ & $98 \pm 0.02$ & $99 \pm 0.02$ & $100 \pm 0.01$ \\
\hline
\end{tabular}

Table 5: In vitro release profile of lornoxicam core tablets.

\begin{tabular}{cccccc}
\hline S. & Time in & \multicolumn{4}{c}{ Cumulative percentage release of core tablet } \\
\cline { 3 - 6 } No & Minutes & C1 & C2 & C3 & C4 \\
\hline 1 & 5 & $23 \pm 0.1$ & $27 \pm 0.3$ & $26 \pm 0.78$ & $32 \pm 0.98$ \\
2 & 10 & $26 \pm 0.2$ & $36 \pm 0.26$ & $42 \pm 0.74$ & $45 \pm 0.91$ \\
3 & 15 & $34 \pm 0.25$ & $45 \pm 0.3$ & $51 \pm 0.70$ & $56 \pm 0.94$ \\
4 & 20 & $44 \pm 0.15$ & $59 \pm 0.3$ & $71 \pm 0.73$ & $78 \pm 0.90$ \\
\hline
\end{tabular}

Table 6: Composition of lornoxicam compression coated tablet.

\begin{tabular}{ccccccc}
\hline \multirow{2}{*}{$\begin{array}{c}\text { S. } \\
\text { No }\end{array}$} & \multirow{2}{*}{ Ingredients } & \multicolumn{5}{c}{ Formulation codes of press coat tablet (mg/tab) } \\
\cline { 3 - 7 } & CC $\mathbf{~}$ & CC $\mathbf{2}$ & CC 3 & CC 4 & CC 5 \\
\hline 1 & Core tablet & 100 & 100 & 100 & 100 & 100 \\
2 & HPMC & 0 & 50 & 100 & 150 & 200 \\
3 & Ethyl cellulose & 200 & 150 & 100 & 50 & 0 \\
4 & Total weight & 300 & 300 & 300 & 300 & 300 \\
\hline
\end{tabular}

Table 7: Evaluation of Lornoxicam Compression coated tablets.

\begin{tabular}{|c|c|c|c|c|c|c|}
\hline \multirow{2}{*}{$\begin{array}{l}\text { S. } \\
\text { No }\end{array}$} & \multirow{2}{*}{ Parameters } & \multicolumn{5}{|c|}{ Coated Tablet } \\
\hline & & $\mathrm{CCl}$ & $\mathrm{CC} 2$ & $\mathrm{CC} 3$ & $\mathrm{CC} 4$ & $\mathrm{CC5}$ \\
\hline 1 & Thickness mm & $4.5 \pm 0.11$ & $4.6 \pm 0.14$ & $4.5 \pm 0.11$ & $4.7 \pm 0.12$ & $4.5 \pm 0.12$ \\
\hline 2 & Hardness $\mathrm{Kg} / \mathrm{cm}^{2}$ & $6.4 \pm 0.00$ & $6.5 \pm 0.01$ & $6.8 \pm 0.01$ & $6.1 \pm 0.02$ & $6.0 \pm 0.01$ \\
\hline 3 & Weight Deviation \% & $300.08 \pm 0.01$ & $299.25 \pm 0.01$ & $298.27 \pm 0.02$ & $299.20 \pm 0.05$ & $300.85 \pm 0.03$ \\
\hline 4 & Friability\% & 0.5 & 0.5 & 0.7 & 0.7 & 0.7 \\
\hline 5 & Drug content $\%$ & 97.6 & 96.36 & 98.80 & 98.7 & 97.9 \\
\hline 6 & Swelling index $\%$ & 78 & 94 & 132 & 112 & 127 \\
\hline
\end{tabular}

Table 8: In vitro drug release $\%$ from press coated tablet.

\begin{tabular}{|c|c|c|c|c|c|c|}
\hline \multirow{2}{*}{ Time (hrs) } & \multirow{2}{*}{ Media } & \multicolumn{5}{|c|}{ \% Cumulative drug release } \\
\hline & & CC1 & $\mathrm{CC} 2$ & CC3 & $\mathrm{CC} 4$ & CC5 \\
\hline 1 & & 0 & 0 & 0 & 0 & 0 \\
\hline 2 & $0.1 \mathrm{~N} \mathrm{HCl}$ & 0 & 0 & 0 & 0 & $7.4 \pm 0.28$ \\
\hline 3 & & $10.4 \pm 0.51$ & 0 & 0 & 0 & $10.4 \pm 0.26$ \\
\hline 4 & & $12.5 \pm 0.32$ & $18.5 \pm 0.1$ & 0 & 0 & $17.2 \pm 0.37$ \\
\hline 5 & & $15.2 \pm 0.41$ & $39.6 \pm 0.52$ & 0 & $26.7 \pm 0.52$ & $29.5 \pm 0.51$ \\
\hline 6 & pH 6.8 & $18.3 \pm 0.32$ & $52.4 \pm 0.37$ & $15.5 \pm 0.15$ & $39.1 \pm 0.25$ & $45.6 \pm 0.17$ \\
\hline 7 & Phosphate buffer & $24.6 \pm 0.41$ & $60.3 \pm 0.26$ & $48.9 \pm 0.17$ & $62.4 \pm 0.34$ & $58.4 \pm 0.20$ \\
\hline 8 & & $35.8 \pm 0.17$ & $72.2 \pm 0.15$ & $72.4 \pm 0.20$ & $71.1 \pm 0.37$ & $63.9 \pm 0.20$ \\
\hline 9 & & $47.5 \pm 0.14$ & $80.3 \pm 0.35$ & $97.5 \pm 0.40$ & $79.1 \pm 0.36$ & $73.7 \pm 0.41$ \\
\hline
\end{tabular}

Table 9: Data of release kinetics.

\begin{tabular}{|c|c|c|c|c|c|c|c|}
\hline \multicolumn{2}{|c|}{ Zero order } & \multicolumn{2}{|c|}{ First order } & \multicolumn{2}{|c|}{ Higuchi } & \multicolumn{2}{|c|}{ Korse Meyer } \\
\hline 0 & 0 & 0 & 0 & 0 & 0 & 0 & 0 \\
\hline 1 & 0 & 1 & 2 & 1 & 0 & 0 & 0 \\
\hline 2 & 0 & 2 & 2 & 1.414213562 & 0 & 0.301029996 & 0 \\
\hline 3 & 7.4 & 3 & 1.966610987 & 1.732050808 & 7.4 & 0.477121255 & 0.86923172 \\
\hline 4 & 10.4 & 4 & 1.95230801 & 2 & 10.4 & 0.602059991 & 1.017033339 \\
\hline 5 & 17.2 & 5 & 1.918030337 & 2.236067977 & 17.2 & 0.698970004 & 1.235528447 \\
\hline 6 & 29.5 & 6 & 1.848189117 & 2.449489743 & 29.5 & 0.77815125 & 1.469822016 \\
\hline 7 & 45.6 & 7 & 1.7355989 & 2.645751311 & 45.6 & 0.84509804 & 1.658964843 \\
\hline 8 & 63.9 & 8 & 1.557507202 & 2.828427125 & 63.9 & 0.903089987 & 1.805500858 \\
\hline 9 & 73.7 & 9 & 1.419955748 & 3 & 73.7 & 0.954242509 & 1.867467488 \\
\hline
\end{tabular}


Table 10: In-vitro dissolution studies of the optimized formulation at $40 \pm 2{ }^{\circ} \mathrm{C} / 75 \% \mathrm{RH}$.

\begin{tabular}{|c|c|c|c|c|c|c|c|}
\hline \multirow{2}{*}{$\begin{array}{l}\text { S. } \\
\text { No }\end{array}$} & \multirow{2}{*}{$\begin{array}{c}\text { Sampling interval } \\
\text { (Days) }\end{array}$} & \multirow{2}{*}{$\begin{array}{c}\text { Hardness } \\
\left(\mathrm{Kg} / \mathrm{cm}^{2}\right)\end{array}$} & \multirow{2}{*}{$\begin{array}{c}\text { Drug } \\
\text { content }(\%)\end{array}$} & \multicolumn{3}{|c|}{$\%$ Drug release during $9 \mathrm{hr}$} & \multirow{2}{*}{$\begin{array}{c}\text { Organoleptic } \\
\text { properties }\end{array}$} \\
\hline & & & & $25^{\circ} \mathrm{C} / 60 \% \mathrm{RH}$ & $30^{\circ} \mathrm{C} / 70 \% \mathrm{RH}$ & $45^{\circ} \mathrm{C} / 75 \% \mathrm{RH}$ & \\
\hline 1 & 0 & 6.8 & 98.80 & 97.5 & 97.5 & 97.5 & White \\
\hline 2 & 30 & 6.8 & 98.80 & 97.4 & 97.06 & 97.1 & White \\
\hline 3 & 60 & 6.7 & 98.74 & 97.1 & 96.55 & 96.9 & White \\
\hline 4 & 90 & 6.7 & 98.70 & 96.4 & 95.40 & 96.0 & White \\
\hline
\end{tabular}

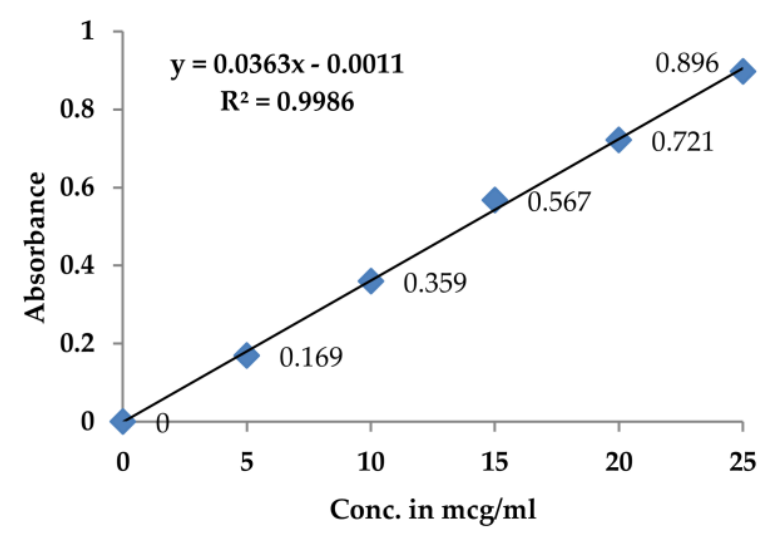

Figure 1: Calibration curve of lornoxicam.

found at $1641.49 \mathrm{~cm}^{-1}$ due to stretching vibration of the $\mathrm{C}=\mathrm{O}$ group in primary amide. Other peaks were observed at1593.25 and $1541.18 \mathrm{~cm}^{-1}$ and were assigned to bending vibrations of the $\mathrm{N}-\mathrm{H}$ group in the secondary amide. The stretching vibrations of the $\mathrm{O}=\mathrm{S}=\mathrm{O}$ group appeared at1149.61, 1381.09 and $1327.07 \mathrm{~cm}^{-1}$. Other peaks appeared at $829.42 \mathrm{~cm}^{-1}$ corresponding to $-\mathrm{CH}$ aromatic ring bending and hetero aromatics and at $781.20 \mathrm{~cm}^{-1}$ due to $\mathrm{C}$ $\mathrm{Cl}$ bending vibrations. FTIR spectra of compressed coated tablets have got lot of similarities with IR spectra of pure drug. It was clear from the spectra that the change in position of characteristic bands of the drug molecule was negligible and was within the limit of the absorption range, which indicates the formulation showed no disappearance of the peaks or the shift of the peaks indicating that the drug is compatible with all ingredients (figure 1,2).

The core tablets were evaluated for pre and post compression parameters. The granules used for preparing the core tablets of lornoxicam were evaluated for angle of repose, bulk density, tapped density, compressibility index, and Hausner's ratio. The angle of repose was found to be in the range of $25.55 \pm 0.03$ to $28.08 \pm 0.02$ exhibited the excellent flow properties. The packing properties of the material can be evaluated by the bulk and tapped density. The bulk density and tapped density were $0.43 \pm 0.01$ to $0.47 \pm 0.02 \mathrm{gm} / \mathrm{mL}$ and $0.50 \pm 0.015$ to $0.54 \pm 0.02 \mathrm{gm} / \mathrm{mL}$, respectively, which indicate good flowability of the granules (Soppimath et al., 2001) Carr's index was found to be $12.48 \pm 0.27$ to $12.89 \pm 0.14$ and Hausner's ratio $1.13 \pm 0.022$ to $1.17 \pm 0.010$ the above results indicates that the granules formed were easily compressible.

The post compression parameters of prepared lornoxicam core tablets were depicted in (table 4). The weight variation values for all formulations (C1 to C4) were found between $98 \pm 0.02$ to $100 \pm 0.01 \mathrm{mg}$. All the weight variation values of tablets were complying with

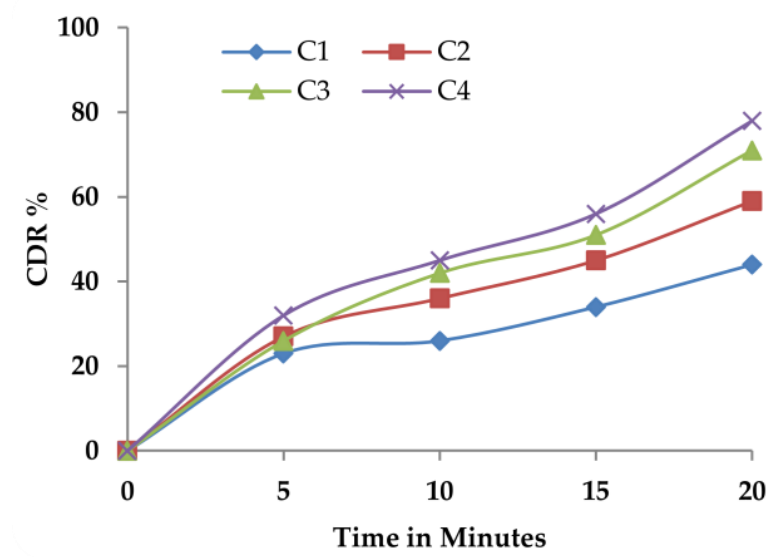

Figure 2: In vitro release profile of lornoxicam core tablets.

official limits. The mean thickness of all the formulated batches of tablets was measured, and the results were noticed in the range of $2.4 \pm 0.17$ to $2.6 \pm 0.11$. The friability of the batches was between 0.7 to $0.8 \%$, respectively. Furthermore, the percentage friability that was less than $1 \%$ indicates that the friability is within the specified limit. The hardness of the core tablet usually kept low, that is, $3.5 \pm 0.15$ to $3.8 \pm 0.17$ so that press-coated polymer granules of HPMC and Ethyl cellulose get sticks to the core tablet (Gohel et al., 2008). All the formulations showed maximum \% drug content, that is, $97.28 \pm 0.02$ to $100.25 \pm 0.01$. Tablets from all the batches were completely disintegrated less than 35 seconds and the values were found to be $18 \pm 0.02$ to $32 \pm 0.05$ respectively. The dissolution profile of core tablet was studied in phosphate buffer $\mathrm{pH} 6.8$ to limit the release profile of the core tablet. It was found that all the batches of lornoxicam core tablets showed drug release between $44-78 \%$ within 20 minute. The maximum drug release was obtained from batch $\mathrm{C} 4$ having the highest concentration of superdisintegrant $10 \%$ (CCS). The amount of drug released exhibited a direct relationship with the amount of CCS in core tablet. Above said batch was selected as an optimized batch for further process of compression coating because it showed fast disintegration time of 18 seconds and rapid dissolution of $78 \%$ than other formulations.

Five batches of compressed coated tablets of lornoxicam (CC1- CC5) were formulated by coating of polymeric granules over core tablet. These tablets were film coated to enhance appearance. Coating solution containing Eudragit produced tablets with glossy appearance and concealed surface imperfection.

All the physical properties of lonoxicam compression coated tablets were given in table 7 . From the weight variation test, it was found that the weight variation of the tablets was in the range of $298.27 \pm 0.02 \mathrm{mg}$ to $300.85 \pm 0.03$ $\mathrm{mg}$. The hardness of the tablets was found to be in the 


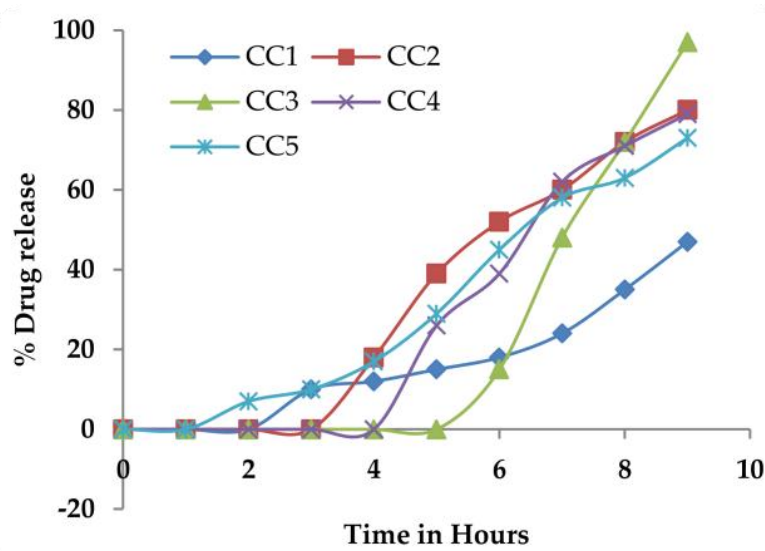

Figure 3: Lornoxicam release profile of compressed coated tablets.

range of $6.0 \pm 0.01 \mathrm{~kg} / \mathrm{cm}^{2}-6.8 \pm 0.0101 \mathrm{~kg} / \mathrm{cm}^{2}$. The percentage friability for all formulations was below $1 \%$, that is, $0.5-$ $0.7 \%$ indicating that the friability is within the prescribed limits. The tablets were found to contain $96.36-98.8 \%$ of the labeled amount indicating uniformity of drug content.

All the formulations, the compression coat weight were set at $200 \mathrm{mg}$. All batches of lornoxicam shows the pulsatile release behavior with distinct lag time between (2-3 hr). Figure 3 showed the release profiles of lornoxicam from the compression coated tablets. It was found that the percent of drug release was increased gradually after $5 \mathrm{~h}$, the cumulative percent of lornoxicam released from compression coated tablets containing varying amounts of coating materials of HPMC \& EC (50 $\mathrm{mg}, 100 \mathrm{mg}, 150 \mathrm{mg}$ and $200 \mathrm{mg}$ ), with incorporation of $100 \mathrm{mg}$ of each of the polymers of HPMC \& EC was found to be satisfactory to formulate a tablet with good integrity and satisfactory in vitro drug release.

A pulsatile drug delivery system is characterized by a lag time that is an interval of no drug release followed by rapid drug release (Kikuchi and Okano, 2002). Hydrophilic and hydrophobic polymers have been investigated in this study to evaluate the effect on lag time. From the dissolution study it is observed that when the polymers used alone (CC1 and CC 5) has shown optimal lag period with burst at $2 \mathrm{~h}$ and $1 \mathrm{~h}$ drug release $47 \%$ and $73 \%$, respectively at the end of $9 \mathrm{~h}$. Coating polymeric granules was mixed together in batches $\left(\mathrm{CC}_{2}\right.$, $\mathrm{CC}_{3}$ and $\mathrm{CC}_{4}$ ) to achieve high lag time with minimum drug release. Formulation batch $\mathrm{CC}_{2}$ and $\mathrm{CC}_{4}$ contained $16 \%$ of EC and $50 \%$ HPMC, and vice versa. These two formulations extending lag period with burst at 3 and $4 \mathrm{~h}$ and drug release $80 \%$ and $79 \%$, respectively. Compression-coated with $50 \%$ of each of the polymeric granules of HPMC and EC extending lag period with burst at $6 \mathrm{~h}$ and drug release of $97 \%$ were noticed at the end of $9 \mathrm{~h}$. The compression of HPMC granules may create viscous thick gel structure around the EC coated core tablets this could be the reason to extend the lag time. Based on all the formulation dissolution studies, we concluded the combination of hydrophilic and hydrophobic polymers
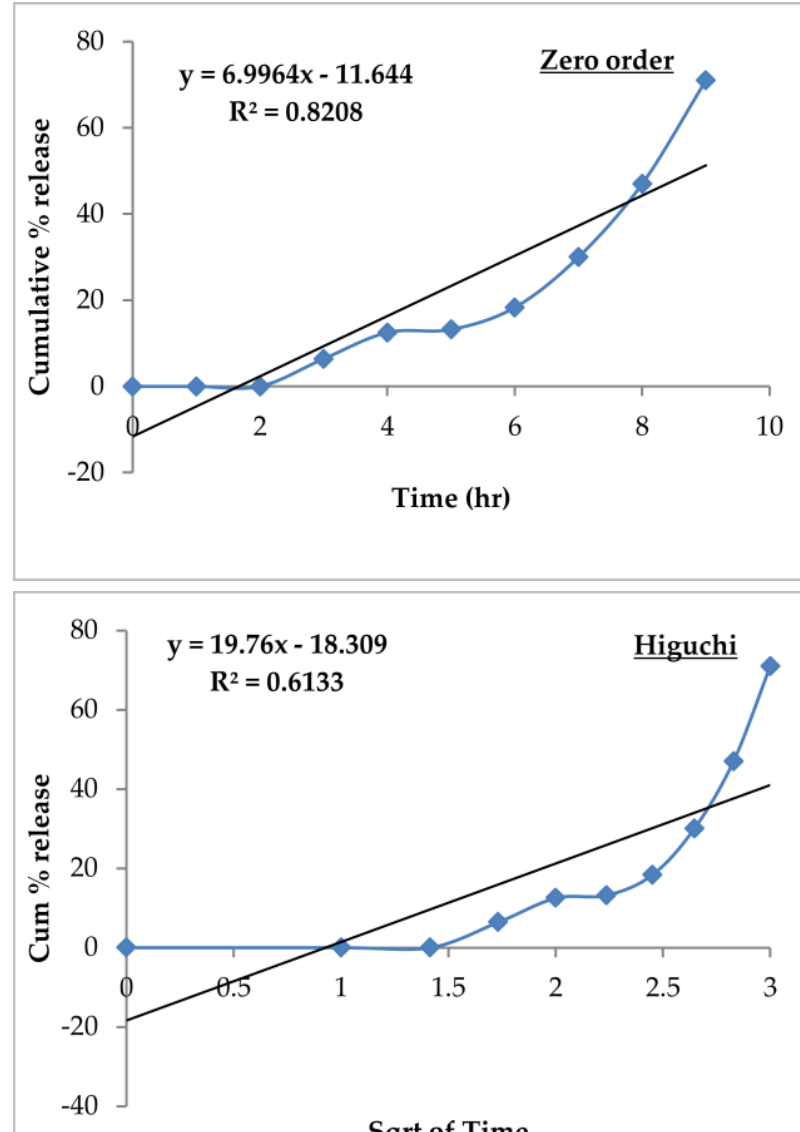
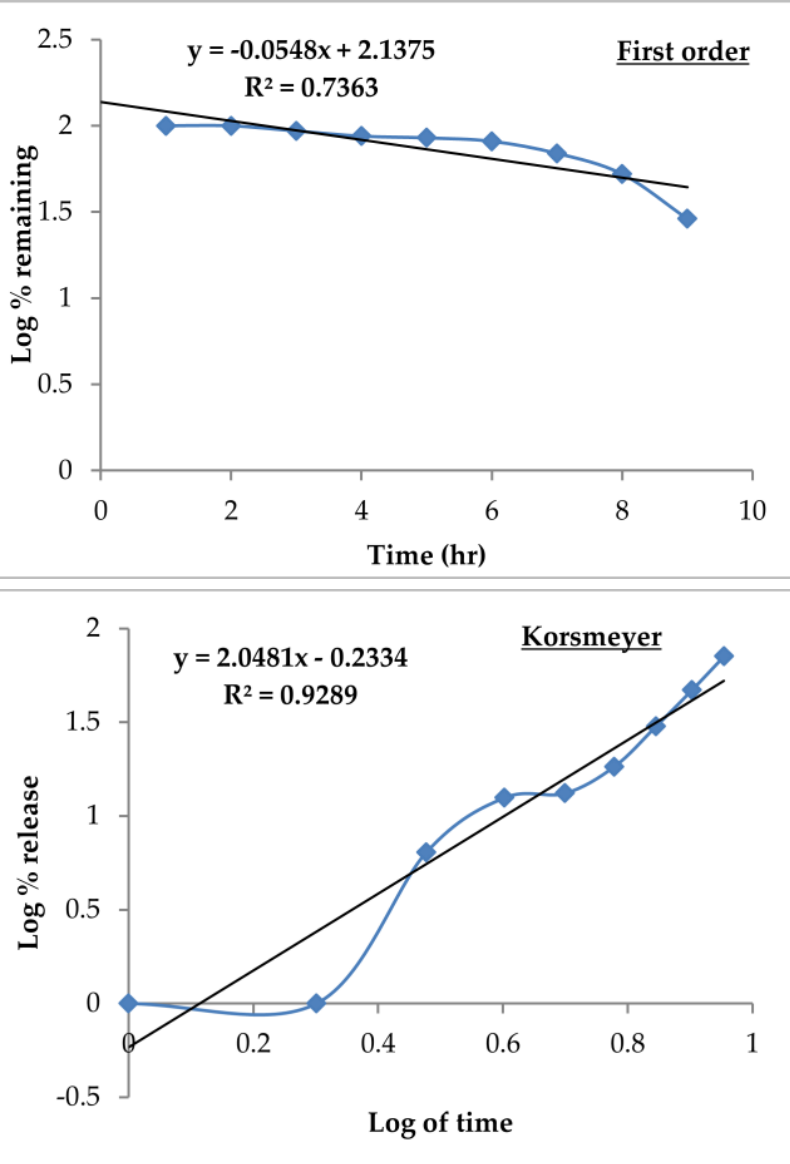

Figure 4: Kinetic modeling of lornoxicam pulsatile release tablets. 
are best to extend the lag time than the individual. Hence, formulation $\mathrm{CC}_{3}$ with $33 \%$ HPMC and 33\% EC was found to be most promising formulation and maintained excellent lag period, thus selected as the optimized formulation.

The drug release kinetic data of press coated tablet of lornoxicam is shown in table 8. From the graphical representation (figure 4), it can be inferred that this is a best fit in to korsmeyer which had shown a regression coefficient $\left(\mathrm{R}^{2}\right)$ of 0.9289 . The results of the in vitro release data of these were fitted to the Korsmeyer-Peppa's equation to analyze the release pattern of the drug from the polymeric system. The value of " $n$ " was found to be more than 0.89, indicating the drug release follows super case II transport.

The optimized tablets from batch $\mathrm{CC}_{3}$ were charged for stability studies at $40^{\circ} \mathrm{C}$ and $75 \% \mathrm{RH}$. There was no change in physical appearance, color. The formulations were analyzed for the period of 3 months for general tablet properties such as weight variation, thickness, hardness, friability, drug content and in vitro dissolution studies. Tablets have shown no much deviation in hardness, friability values.

The average drug content of the tablets was found to be $99.5 \pm 0.05 \%$. The in vitro dissolution profile of optimized formulation has demonstrated no substantial change in the discharge rate of the drug in the period of 3 months. It indicates good stability of press coated lornoxicam tablets (CC3). This shows that the lornoxicam tablets are suitable for the manufacturing as a tablet without any problems as a pulsatile release formulation.

\section{CONCLUSION}

As we have referred in the introduction that our objective was to target lornoxicam release in the early morning hours as per chronotherapy. By keeping this concept in view we have successfully formulated a pulsatile dosage form by compression coating of lornoxicam core tablets by combination of HPMC and Ethyl cellulose polymer granules. Formulation $\mathrm{CC} 3$ was considered as the best formulation as it releases $15.5 \pm 0.15$ and $97.5 \pm 0.40 \%$ of lornoxicam at the end of 6 and 8 hours, respectively. This release profile is based on the assumption that if the patient takes this optimized formulation at 10:00 P.M (i.e., before going to bed) then the drug starts releasing after a lag time 6 hours and almost all portion of the drug will be released in between 4-7 A.M. Thus, maximum drug will be available for targeting early morning peak symptoms of rheumatoid arthritis.

\section{REFERENCES}

Abhinetri, V., Hadi, M.A., Rao, A.S. and Sravani V. (2013). Development of a Novel Enteric Coated Extended Release Pellets using Model NSAID Flurbiprofen. Intl. J. Pharm. Sci. Res. 4, 754-760.

Agarwal, V., Sharma, PK., Bansal, M. (2011). Chronobiological approach for treatment of rheumatoid arthritis, J. Chronotherapy and Drug Delivery 2, 1-6.

Bajpai, M., Singh, D. C. P., Bhattacharya, A., \& Singh, A. (2012). Design and in vitro evaluation of compression-coated pulsatile release tablets of losartan potassium. Indian journal of pharmaceutical sciences, $74(2)$ 101. [DOI]

Bashardoust, N., Jenita, J. J. L., \& Zakeri-Milani, P. (2013). Physicochemical characterization and dissolution study of ibuprofen compressioncoated tablets using locust bean gum. Dissolution Technologies, 20, 3843. [DOI]

Bendale, A. R., Prajapati, V., Narkhede, S. P., Narkhede, S. B., Jadav, A. G., \& Vidyasagar, G. (2011). Analytical method development \& validation protocol for trospium chloride in tablet dosage form. Indo-Global J Pharm Sci, 1(2), 166-72.
Buttgereit, F. (2011). Chronotherapy with Glucorticoids in Rheumatoid Arthritis. The Rheumatologist, January.

Chithaluru, K, \& Tadikonda, R. R. (2011). Formulation and evaluation of microbially triggered compression coated tablets of ketorolac tromethiamine.Der Pharmacia Lettre, 3(4), 29-39.

Dandale, S.S., Deshmane, S.V., Biyani, K.R. (2013) Formulation and evaluation of pressed coated pulsatile tablet containing nifedipine, International Journal of Biological \& Pharmaceutical Research; 4(7): 471-474.

Gohel, M. C., Soni, C. D., Nagori, S. A., \& Sarvaiya, K. G. (2008). Modulation of venlafaxine hydrochloride release from press coated matrix tablet. Indian journal of pharmaceutical sciences, 70(3), 292. [DOI]

Jagdale, S. C., Sali, M. S., Barhate, A. L., Loharkar, J. N., \& Chabukswar, A. R. (2010). Design and evaluation of enteric press-coated tablet for pulsatile delivery of atenolol. International journal of pharma world research, 1(2), 1-15.

Khamanga, S., \& Walker, R. B. (2011). Drug transport mechanisms from carbopol/eudragit verapamil sustained-release tablets. Dissolut Technol, 18, 30-38. [DOI

Kidd, B., Frenzel, W. (1996). A multicenter, randomized, double blind study comparing lornoxicam with diclofenac in osteoarthritis. J. Rheumatol. 23, 1605-1611. PMid:8877932

Kikuchi, A., \& Okano, T. (2002). Pulsatile drug release control using hydrogen. Advanced drug delivery reviews, 54 (1), 53-77. [DOI]

Mothilal, M., Swati, PS., Shaik Nelofar., Damodharan, N., Manimaran, V., Lakshmi, KS. (2012). Formulation and evaluation of aceclofenac compression coated tablets for colon drug delivery. Res. J. Pharm. Bio. Chem. Sci. 3:1062-1071.

Najmuddin, M., Vishal Ashok Patel., Azgar Ali., Shelar, S., Tousif, K (2010). Development and evaluation of pulsatile drug delivery system of flurbiprofen. Res. J. Pharm. Bio. Chem. Sci. 1, 289-290.

Narendra, C. and Srinath, M.S. (2010). Study the effect of formulation variables in the development of timed-release press-coated tablets by Taguchi design. Nat. Sci. 2, 379-387. [DOI]

Rajput, M., Ritika, Sharma., Sunil Kumar., Faraz Jamil., Neeraj Sissodia, Saurabh Sharma. (2012). Pulsatile drug delivery system - a review. Int Journal Rese. Pharma and Biomedical Sciences. 3:118-124.

Rane, A. B., Gattani, S. G., Kadam, V. D., \& Tekade, A. R. (2009) Formulation and evaluation of press coated tablets for pulsatile drug delivery using hydrophilic and hydrophobic polymers. Chemical and Pharmaceutical Bulletin, 57(11), 1213-1217. [DOI]

Rao, N. R., Hadi, M. A., \& Panchal, H. A. (2011). A novel approach to sustained montelukast sodium release: Differentially coated minitablets in HPMC capsules. International Journal of Pharmaceutical and Biomedical Sciences, 2(2), 90-97.

Sharma, P., Chawla, A., \& Pawar, P. (2013). Design, Development, and Optimization of Polymeric Based-Colonic Drug Delivery System of Naproxen.The Scientific World Journal, 2013. [DOI]

Singh, A., Dubey, H., Shukla, I., Singh, D.P. (2012). Pulsatile drug delivery system: an approach of medication according to circadian rhythm. J. App. Pharm. Sci. 02, 166-176.

Soppimath, K. S., Kulkarni, A. R., \& Aminabhavi, T. M. (2001). Chemically modified polyacrylamide-g-guar gum-based crosslinked anionic microgels as $\mathrm{pH}$-sensitive drug delivery systems: preparation and characterization. Journal of Controlled Release, 75(3), 331-345. [DOI]

Thakkar, V. T., Shah, P. A., Soni, T. G., Parmar, M. Y., Gohel, M. C., \& Gandhi, T. R. (2009). Goodness-of-fit model-dependent approach for release kinetics of levofloxacin hemihydrates floating tablet. Dissolution Technologies, 16(1), 35-39. [DOI]

Zhang, Y., Zhong, D., Si, D., Guo. Y., Chen, X., Zhou, H. (2005). Lornoxicam pharmacokinetics in relation to cytochrome P450 2C9 genotype. Br. J. Clin. Pharmacol. 59, 14-17. [DOI] 